\title{
Support for a common metric for pediatric pain intensity scales
}

\author{
Carl L von Baeyer $\mathrm{PhD}^{1,2}$, Carrie L Hicks BA ${ }^{1}$
}

CL von Baeyer, CL Hicks.

Support for a common metric for pediatric pain intensity scales.

Pain Res Manage 2000;4(2):157-160.

Institutional adoption of routine measurement of pediatric pain has been impeded partly by the profusion of different metrics (eg, 0 to 5,0 to 6,0 to 10,0 to 100 ) for reporting pain intensity on various instruments. The present paper discusses the importance of adopting a common metric, that is, a single numbering system on which estimates of pain intensity from various sources can be recorded. To explore both support and reservations concerning the adoption of a common metric, a survey questionnaire was sent in 1999 to an estimated 600 subscribers to the Pediatric Pain Internet Mailing List. Individuals working in pediatric institutions where children's pain is routinely measured, or where adoption of such measures is planned, were requested to respond by e-mail or mail. Responses $(n=37)$ were from nurses $(49 \%)$, physicians $(24 \%)$, psychologists (7\%) and others/unlisted (20\%) on four continents. Adoption of a common metric was endorsed by $81 \%$ of respondents. Among the possible numbering systems, the 0 to 10 system was strongly favoured $(70 \%)$ over other options. Respondents commented that adoption of a common metric would improve communication and consistency in measurement both within and among institutions. Some disadvantages, such as staff resistance to altering existing systems, were also suggested. The majority of respondents thought that it would be desirable to adopt a common metric. Among the possible numbering systems, the 0 to 10 system is by far the most favoured. Adopting a common 0 to 10 standard, and adapting existing tools to that metric, would be positive steps toward identifying and relieving children's pain.

Key Words: Children; Intensity; Measurement; Pediatric pain; Scale

\section{Échelles de la douleur chez les enfants : en faveur d'un système commun}

RÉSUMÉ : L'adoption d'une échelle uniforme de la douleur chez les enfants dans les établissements a été entravée en partie par l'existence d'une multitude de systèmes, variant par exemple de 0 à 5 , de 0 à 6 , de 0 à 10 ou de 0 à 100 , pour évaluer l'intensité de la douleur selon différents instruments. Le présent article traite de l'importance d'adopter un système commun, c'est-à-dire un système unique de numérotation, fondé sur l'évaluation de l'intensité de la douleur à partir de différents instruments. Un questionnaire a été envoyé en 1999 à quelque 600 abonnés de la Pediatric Pain Internet Mailing List afin de recueillir leur avis sur la pertinence et les difficultés d'adopter un système commun. On demandait aux personnes travaillant dans des établissements où la mesure de l'intensité de la douleur chez les enfants était pratique courante ou était envisagée d'envoyer leurs réponses par la poste ou par courrier électronique. Il y a eu 37 répondants : $49 \%$ d'infirmières, $24 \%$ de médecins, $7 \%$ de psychologues et $20 \%$ d'autres catégories, et ce, sur quatre continents. Quatre-vingt-un pour cent des répondants se sont déclarés en faveur de l'adoption d'un système unique. Parmi les différentes possibilités, l'échelle de 0 à 10 a fait l'objet d'un large consensus, soit $70 \%$. Les répondants ont fait valoir que l'adoption d'un système unique améliorerait les communications et l'uniformité des mesures aussi bien dans les établissements qu'entre les établissements. Parmi les inconvénients relevés, notons la résistance du personnel au changement. Toutefois, la majorité des répondants estime qu'il serait souhaitable d'adopter un système unique, et c'est l'échelle de 0 à 10 qui, de loin, a recueilli l'appui le plus important. L'adoption d'un système unique et l'adaptation des instruments actuels constitueraient une étape importante vers l'évaluation et le soulagement de la douleur chez les enfants.

\footnotetext{
${ }^{1}$ Department of Psychology, ${ }^{2}$ Department of Pediatrics, University of Saskatchewan, Saskatoon, Saskatchewan

Correspondence and reprints: Dr Carl L von Baeyer, Department of Psychology, University of Saskatchewan, 9 Campus Drive, Saskatoon, Saskatchewan S7N 5A5. Fax 306-966-6630, e-mail carl.vonbaeyer@usask.ca
} 


\section{SUPPORT FOR A COMMON METRIC FOR PEDIATRIC PAIN INTENSITY SCALES}

Progress in science and medicine has been facilitated by the development of widely accepted units such as the gram, second and metre of the Système Internationale. In the field of human differences, a person's intelligence quotient (IQ) may be measured by a Stanford-Binet, a Wechsler or any of a number of other tests, but the IQ score is universally recorded and communicated using the same scale. If every different IQ test used a different metric, or if different metrics were used for persons of different ages or clinical conditions, then communication about intellectual functioning would be slowed, and confusion and errors would be frequent.

Pediatric pain measurement is still in its infancy. Different metrics abound because developers of new pain measures have generally employed whatever metric was convenient without calibration onto a common scale. Metrics employed in published self-report and observational pain intensity measures include, among others, the diverse examples cited in Table 1. Most instruments employ 0 for no pain, but the top anchors range from 4 to 160 .

The profusion of different pediatric pain intensity scales has consequences for both individual patient care and system-wide adoption of good pain measurement practices. At the individual level, in some institutions a pain score of 5 may mean a lot of pain (if a 0 to 5 scale is used) or very little (if a 0 to 100 scale is used), and the protocol may not clearly indicate which score corresponds to which scale. At the system level, ward staff and administrators who do not specialize in pediatric pain may be baffled by the plethora of available instruments and scoring methods, and be unsure which to adopt. The lack of a common metric contributes to the complexity of implementing such clinical innovation, which slows its adoption (1).

The present paper discusses the possibility of adopting a common metric in pediatric pain measurement. The term 'common metric' refers to a numbering system such as ' 0 to

TABLE 1

Examples of diverse metrics used in pediatric pain measurement

\begin{tabular}{lc}
\hline Scale (minimum-maximum) & Reference \\
\hline $0-4$ & 5 \\
$0-5$ & 6 \\
$0-6$ & 4 \\
$0-7$ & 7 \\
$0-10$ & 8,9 \\
$4-13$ & 10 \\
$0-60$ & 11 \\
$0-100$ & 12 \\
$0-160$ & 13 \\
\hline
\end{tabular}

5 ' or ' 0 to 10 ' that can be used to report pain measured by different self-report and observational instruments. Although the numbers might have somewhat different meanings on the different instruments, the zero-pain point and the maximum score would be consistent across instruments. To enhance our understanding of the degree to which a common metric may be supported, and which scales are favoured in the field of pediatric pain, a survey was developed, piloted and distributed to participants in the Pediatric Pain Internet Mailing List (2).

\section{SURVEY}

The 10-item questionnaire (available from the first author) elicited information about pain measurement practices in respondents' institutions, including which measures and metrics are typically used, where pain scores are recorded in patient charts and what efforts have been made to place different measures on the same metric. A series of open-ended questions elicited opinions about the feasibility and importance of developing and implementing a common metric within the respondents' institutions; respondents were specifically asked to identify both advantages and disadvantages of a common metric system. Respondents were also asked to rank a list of six potential common metric scales (Table 2) from most to least preferred. Pilot testing with four pain clinicians resulted in improved wording; the final questionnaire took approximately $10 \mathrm{~min}$ to complete.

The Pediatric Pain Internet Mailing List had approximately 600 subscribers at the time of this survey. For two reasons, an accurate estimate of response rate was not possible there was no way to determine how many people received the survey during the study period, and participants were asked to self-select based on whether they were working in an institution where children's pain is measured or where use of such measures is planned. Therefore, an unknown number of list subscribers did not respond because they did not meet one of these criteria.

Respondents ( $\mathrm{n}=37$ ) were nurses $(49 \%)$, physicians

TABLE 2

Summary of respondents' first choice for a common metric

\begin{tabular}{lcc}
\hline Metric & $\begin{array}{c}\text { Number of first-choice } \\
\text { rankings }\end{array}$ & Percentage \\
\hline $0-1$ & 0 & 0 \\
$0-4$ & 1 & 3 \\
$0-5$ & 5 & 14 \\
$0-6$ & 2 & 5 \\
$0-10$ & 26 & 70 \\
$0-100$ & 2 & 5 \\
Other & 1 & 3 \\
Total* & 37 & 100 \\
\hline
\end{tabular}

*Two respondents did not provide rankings, while two others ranked two options as top choice 
(24\%), psychologists (7\%) and others/unlisted (20\%). Home countries identified included Australia, Belgium, Canada, Chile, Finland, France, Germany, Sweden and the United States (the latter representing $44 \%$ of respondents who identified their country). Of those who identified the type of institution that they worked in, $62 \%$ were employed in children's hospitals or pediatric tertiary care institutions. Responses from individuals in the investigators' institution or city were not included in order to avoid any local bias.

The majority of respondents (81\%) endorsed adopting a common metric. Among the possible numbering systems, the 0 to 10 system was strongly favoured over other options and was listed as first choice by $70 \%$ of respondents; the next most popular option, 0 to 5, was selected as first choice by only $14 \%$. Several other options, such as 0 to 100 , were selected by $5 \%$ or fewer respondents (Table 2).

In their written responses to open-ended questions, respondents identified a number of potential advantages of developing a common metric. They mentioned improved communication and consistency in measurement both within and between institutions. Also mentioned was the idea that a standard scoring system would help clinicians to determine a 'threshold' number above which intervention with new or stronger treatments (eg, pain score of 4 to 10 for duration $1 \mathrm{~h}$ ) was needed. Others commented that a common metric would facilitate the statistical evaluation of interventions.

The survey also asked for comments on possible disadvantages of using a common metric. Some respondents, particularly those involved in neonatal care, expressed concerns that using a common terminology for pain in children of all ages would be an oversimplification of pain measurement. Others said that it would be difficult to get staff to cooperate if adoption of a common metric would require changing an existing system. Some comments mentioned the unestablished validity of the measures adapted to conform to a common metric.

Two respondents cited a recent and widely used nursing manual in which the use of a common metric is proposed. McCaffery and Pasero (3) suggested the use of a 0 to $10 \mathrm{nu}-$ merical rating scale, with word anchors, together with a sixitem faces scale scored $0,2,4,6,8$ or 10 . It is not necessary, however, to create entirely new measures to achieve the goal of a common metric. Instead, some have adapted existing measures for a common metric system. For example, the present authors have modified the Faces Pain Scale (FPS) (4), which was on the 0 to 6 metric, by reducing it from seven faces to six while maintaining its ratio scale properties. In the original form, the FPS would have been impossible to incorporate into systems using either of the two most popular common metric candidates: 0 to 5 or 0 to 10 . Using the FPS Revised, pain intensity can be recorded using either one of these popular metrics (unpublished data).

The $89 \%$ of respondents who reported using regular pain measurements collectively reported using around 40 different self-report and observational instruments to measure children's pain. No single observational instrument was reported as being used by more than four respondents $(11 \%)$.
Communication and adoption of pain measurement may be impeded by this profusion of instruments as much as by the present lack of a common metric.

\section{DISCUSSION AND CONCLUSIONS}

Communication about pain and adoption of routine pain measurement appear to be impeded by three interrelated factors - the profusion of different instruments available for measuring children's pain; the complexity of scoring some of the observational measures; and the present lack of a common metric. In our experience, each of these factors may have slowed the adoption of pain measurement in many pediatric settings, but the third factor is, in our opinion, the simplest to address.

A large majority of survey respondents $(81 \%)$ reported that it would be desirable to adopt a common metric. Among the possible numbering systems, the 0 to 10 system is by far the most favoured. The potential advantages suggested by respondents, including improved communication and consistency both across and within institutions, appear to outweigh the perceived disadvantages. Although the adoption of a common metric was largely supported, some respondents expressed reservations. These concerns need to be explored and considered before full scale adoption of a common metric.

This survey has certain limitations. No claim can be made that the sample is representative. Mailing list members who responded to the survey were presumably members of the pediatric pain community who had the greatest interest in measurement issues. It would be helpful to obtain a fully representative sample of views on the present question, perhaps by surveying all staff concerned with pediatric pain in one or more institutions. On the other hand, if the present survey were a ballot in an election or a vote on a policy issue, the strong majority vote would be considered decisive without considering whether the voting members were representative of all members. In that sense the results may be considered to have a measure of face validity in guiding future research.

As noted above, it was suggested that an advantage of using a common metric is that a certain score could be considered as a signal to intervene. This suggestion raises a further concern; even with the use of a common metric, it certainly cannot be assumed that a particular score means the same to different people. For example, one patient might feel that analgesic medication should be initiated or increased at a pain score of 3 (on a 0 to 10 scale), while another might prefer to use no drugs below a score of 7 . Such decisions about treatment should be made on an individual basis rather than by assuming some universal meaning for pain scores.

While no assumption of universal meaning can be made, other than perhaps that 0 means no pain, the adoption of a common metric may facilitate research as well as clinical practice. It would be easier to read, interpret and integrate research reports if pain scores were somewhat comparable across studies and instruments. Franck (personal communication) has suggested the development and publication of tables to transform the most widely used pediatric pain scales to a 0 to 10 metric. 
Attaining a consensus on the simplification and standardization of systems, measures and metrics is the initial step in the movement toward developing a consensus about best practice in the measurement of pediatric pain. It is important to keep in mind that the proposed common metric is not another instrument for measuring pain, but rather a standard, ratio-scale numbering system for reporting the results of such instruments. The extent to which scores from various pain measures conform to this theoretical metric is a question to be answered separately for each tool and for each measurement situation. However, in our view, adopting a common 0 to 10 standard, and adapting existing tools to that metric, will be further steps toward identifying and relieving children's pain.

ACKNOWLEDGEMENTS: Appreciation is expressed to Marita McInerney, Patrick McGrath, Belinda Goodenough, David Champion, Allen Finley, Linda Franck, members of the Pediatric Pain Internet Mailing List, an anonymous reviewer for this journal and members of Dr von Baeyer's research team for their assistance at various stages. A poster on this topic was presented at the Fifth International Symposium on Paediatric Pain, London, United Kingdom, June 2000.

\section{REFERENCES}

1. Hester N, Foster R, Jordan-March M, Ely E, Vojir C, Miller K. Putting pain measurement into clinical practice. In: Finley G, McGrath P, eds. Measurement of Pain in Infants and Children. Seattle: IASP Press, 1998:179-98.
2. Pediatric Pain Mailing List. $<$ http://is.dal.ca/ pedpain/ppml/ ppmlist.html $>$ (version current at July 18, 2000).

3. McCaffery M, Pasero C. Pain: Clinical Manual, 2nd edn. Toronto: Mosby, 1999.

4. Bieri D, Reeve R, Champion G, Addicoat L, Ziegler J. The Faces Pain Scale for the self-assessment of the severity of pain experienced by children: development, initial validation, and preliminary investigation for ratio scale properties. Pain 1990;41:139-50.

5. Hester N. The preoperational child's reaction to immunization. Nurs Res 1979;28:250-5.

6. McGrath P, Unruh A. Pain in Children and Adolescents. New York: Elsevier, 1987.

7. Lawrence J, Alcock D, McGrath P, Kay J, MacMurray S, Dulberg C. The development of a tool to assess neonatal pain. Neonatal Netw 1993;12:59-66.

8. Krechel S, Bildner J. CRIES: a new neonatal postoperative pain measurement score. Initial testing of validity and reliability. Paediatr Anaesth 1995;5:53-61.

9. Szyfelbein SK, Osgood PF, Carr DB. The assessment of pain and plasma beta-endorphin immunoactivity in burned children. Pain 1985;22:173-82.

10. McGrath P, Johnson G, Goodman J, Schillinger J, Dunn J, Chapman J. The CHEOPS: A behavioral scale to measure postoperative pain in children. In: Fields H, Dubner R, Cervero F, eds. Advances in Pain Research and Therapy. New York: Raven, 1985:395-402.

11. Gauvain-Piquard A, Rodary C, Rezvani A, Serbouti S. The development of the $\mathrm{DEGR}^{\mathrm{R}}$ : A scale to assess pain in young children with cancer. Eur J Pain 1999;3:165-76.

12. Beyer J. The Oucher: A user's manual and technical report. Evanston: The Hospital Play Equipment Company, 1984.

13. McGrath PA. Pain in Children: Nature, Assessment, and Treatment. New York: Guilford, 1990. 


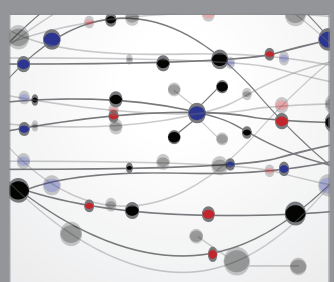

The Scientific World Journal
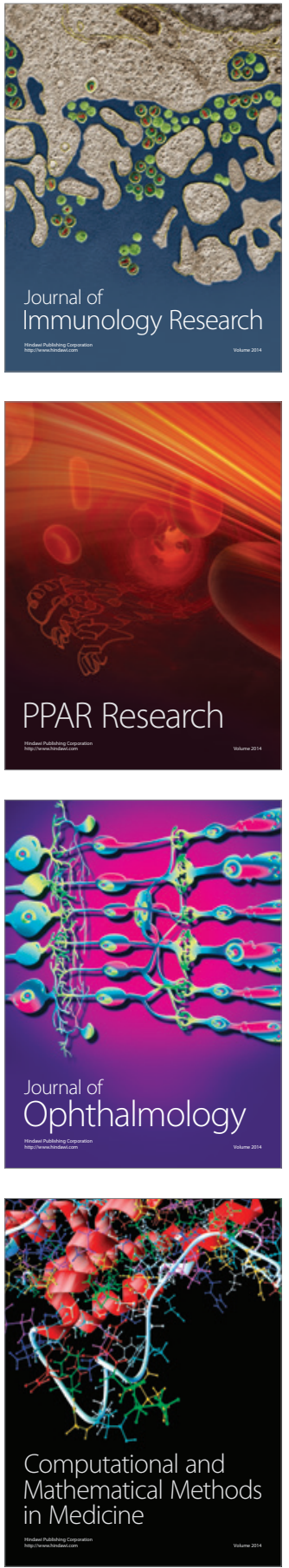

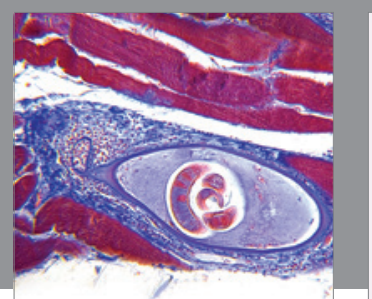

Gastroenterology Research and Practice

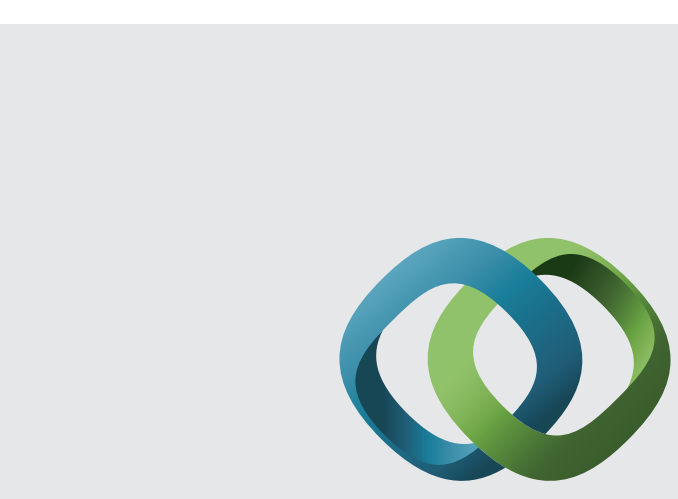

\section{Hindawi}

Submit your manuscripts at

http://www.hindawi.com
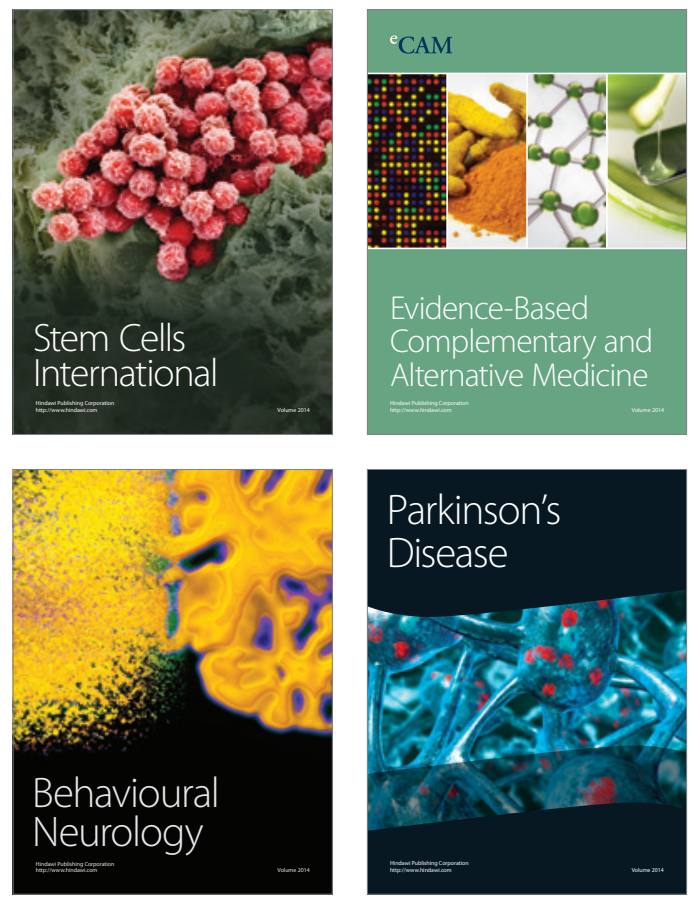
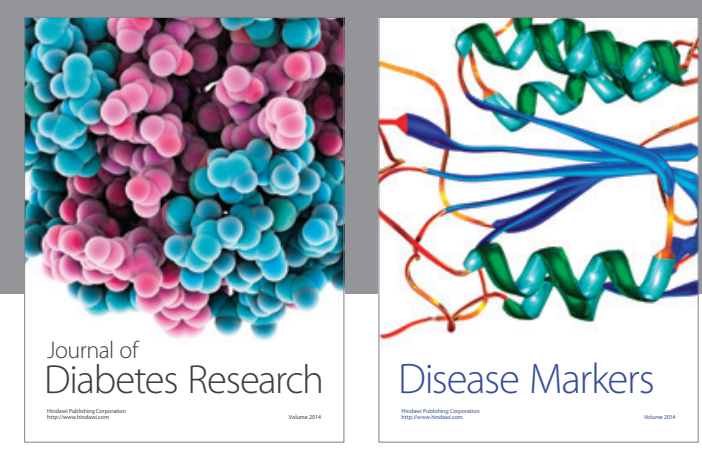

Disease Markers
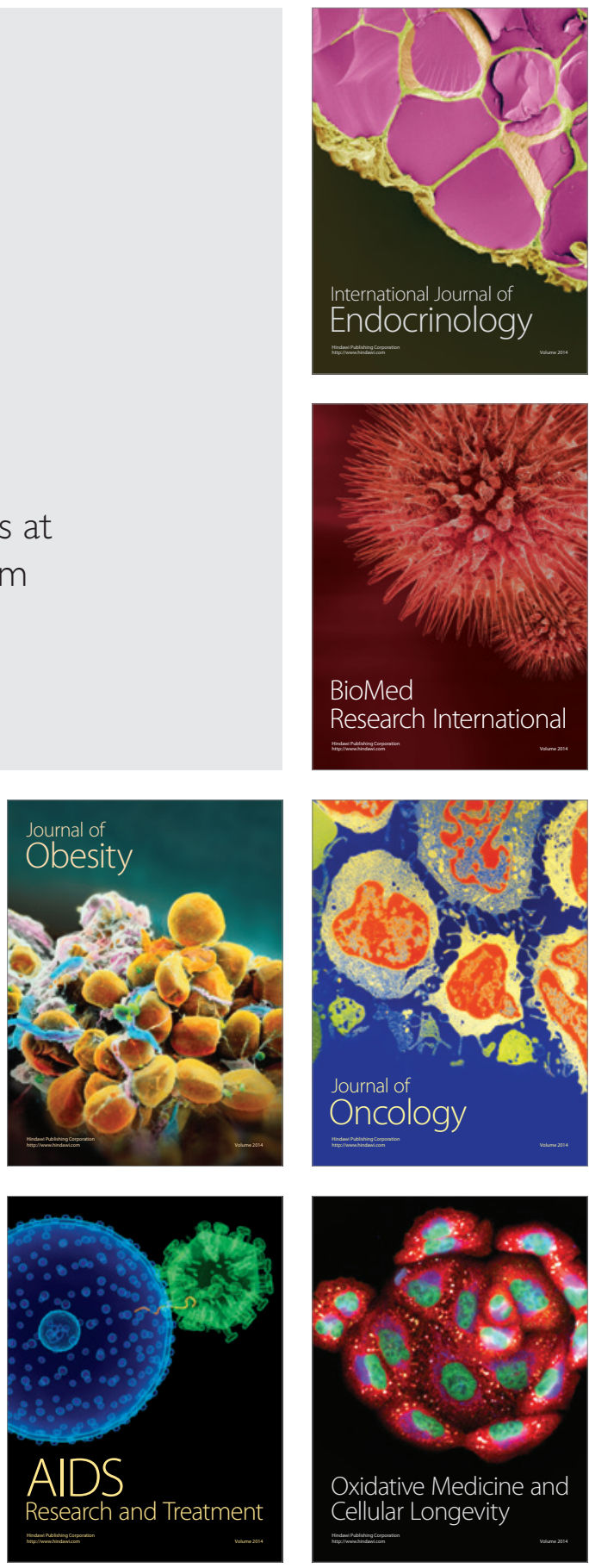